\title{
Pacific Alliance and the Challenge of the Green Economy
}

\author{
Ernesto Rangel, Angel Licona \\ Pacific Basin Studies Center, APEC Study Center of University of Colima, Colima, México \\ Email: erangel@ucol.mx
}

Received 27 December 2014; accepted 10 January 2015; published 16 January 2015

Copyright (C) 2015 by authors and Scientific Research Publishing Inc.

This work is licensed under the Creative Commons Attribution International License (CC BY). http://creativecommons.org/licenses/by/4.0/

c) (i) Open Access

\section{Abstract}

The Pacific Alliance (PA) was constituted on April 28, 2011 by Mexico, Colombia, Chile and Peru. It represents a market of 209 million people with a GDP of over 2 billion USD. It has more than 35 percent of GDP in Latin America and concentrates 50 percent of Latin American exports to the world. PA as regional integration instance that moves progressively to the openness of the movement of goods, services and investments and, shows even more the importance of the Asia Pacific region, whose economic dynamics and competitiveness achieved in the XXI century, presents a greater challenge to Latin American economies. With the integration process that keeps the four countries of the PA, it is necessary to extend cooperation with APEC, particularly in green economy area as an alternative to the challenge of the problems of climate change, the Kyoto protocol and technological change, among others issues, being an alternative to address the deterioration of renewable and nonrenewable resources in the various PEC economies. The authors present the PA as a promising regional integration initiative that should use the experience of APEC to open a field of collaboration that allows the rapprochement between these two regions, in order to promote friendly competition with the environment. The experiences followed by each of the member economies of the PA are presented as a suitable platform to search for mechanisms intra and interregional collaboration that enable green economy that should be aspirated.

\section{Keywords}

Pacific Alliance, Challenge, Green Economy

\section{Introduction}

According to the United Nations Program for Environment (UNEP) report, the main drivers of environmental change in the world in recent years are the population growth and economic development, which lead to limit environmental systems, and placing them in non-stable and dangerous situation. 
Other emissions that pollute the atmosphere and cause major damage in Asia and Latin America are sulfur and nitrogen that contribute to the acidification of waters and for which there is no significant progress in its control.

According to OECD [1] countries, emissions of $\mathrm{CO}_{2}$ for example, are represented (see Figure 1), by industrialized countries, which is understandable because of its economic dynamism and development of technologies that require to be replaced by other environmentally friendly. The high migration costs to a clean technology remain a key factor to carry out that transition. This is a problem that continues on the agenda of the green economy, governmental and NG organizations.

In that sense, authors try to do some explanation in order to take into account the experience of Asia Pacific Economic Cooperation to open a field of collaboration with Pacific Alliance. Following this introduction, the paper shows a theoretical approach explaining the green economy in the economic cooperation framework usually promoting by APEC as in the third part of this paper is showing, especially with some value information regarding to the Latin-American countries members of the PA. Finally, some alternatives to boost the environment care experiences in PA are considered to be close to the Asia Pacific experiences.

\section{Theoretical Approach}

It is the interests of authors that retake the above mentioned problems from the perspective of the PA and outline recent integration in Latin America that has caused a greater expectation among Asia Pacific scholars as this scheme integration makes sense in giving the rapid economic dynamics which has shown recently in the Pacific Rim. Precisely APEC is an important frame that takes into account issues as environment, climate change and sustainable development, on the base of a healthy economic interaction, trade flows and the implementation of new friendly technologies to the environment, moving investments along the region with noticeable effects especially to PA countries.

Thus, the APEC proposed cooperation schemes represent an area of opportunity for integration such as those recently implemented in Latin America. On the basis of these cooperation outlines economies interact globally or regionally, achieving enrich the various activities undertaken to boost their economies; therefore cooperation is critical for states as it includes benefits for more than one nation optimizing resources, various actors allow the exchange of experience building trust and fostering closer relationship between economies to development policies involving to slow down the damage caused by humans to the planet.

To accurately determine the evolution of climate change, organizations such as the Intergovernmental Panel on Climate Change Meteorology [2] and the United Nations Program for Environment (UNEP) have been raised toward maintaining lower global warming to 2 degrees Celsius per year [3], and develop reports on pollution levels and possible solutions to future environmental impact in the commercial economic performance and investment around the world taking up the concept of green economy as a source of clean and friendly business environment.

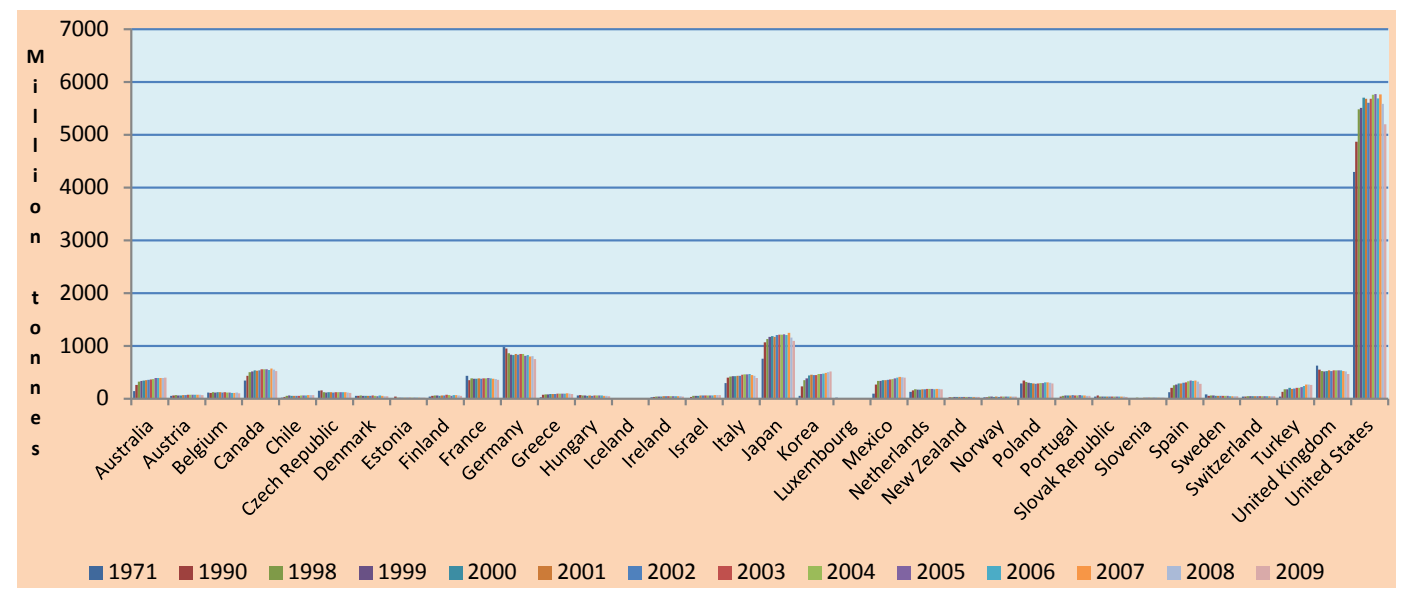

Figure 1. $\mathrm{CO}_{2}$ emissions from fuel combustion in OECD (Source: own calculations using data from the OECD (2014)). 
Thus, UNEP introduced in late 2008 the "Green Economy” initiative in response to Energy, Climate and Food Economic crisis in which humanity is mired in the XXI century. In 2009 was edited the Green New Deal report, or "Global Green New Deal", which proposes publicly and privately develop green sectors and green jobs "greening" that hostile practices against the environment.

A couple of examples (see Figure 2 and Figure 3), show the generation of renewable and nuclear energy, where a noticeable participation of countries such as Iceland, Norway, New Zealand, US, Japan and France, followed by South Korea is observed, but with suspicion, particularly in the case of nuclear energy, due to Fukushima and Chernobyl disasters, resulting however, that the technology contributes little or nothing to the environmental pollution.

Green economy, according to UNEP, is defined as "the system of economic activities related to the production, distribution and consumption of goods and services resulting in human well-being and social equity, and significantly reduces the environmental risks and ecology scarcities". In a simple way, it is also described as the "low-carbon and efficient using resources economy and, socially inclusive." [4].

However, green economy should not be confused with the "sustainable development", whose definition is understood as an integral process, according to the World Commission on Environment and Development, established by the United Nations in 1983, who defined it as "development that meets the needs of the present without compromising the ability of future generations who have to meet their own needs." Sustainable development involves moving from a development plan in quantitative terms - based on economic growth - to a qualitative one, where close links between economic, social and environmental aspects are set in a renewed

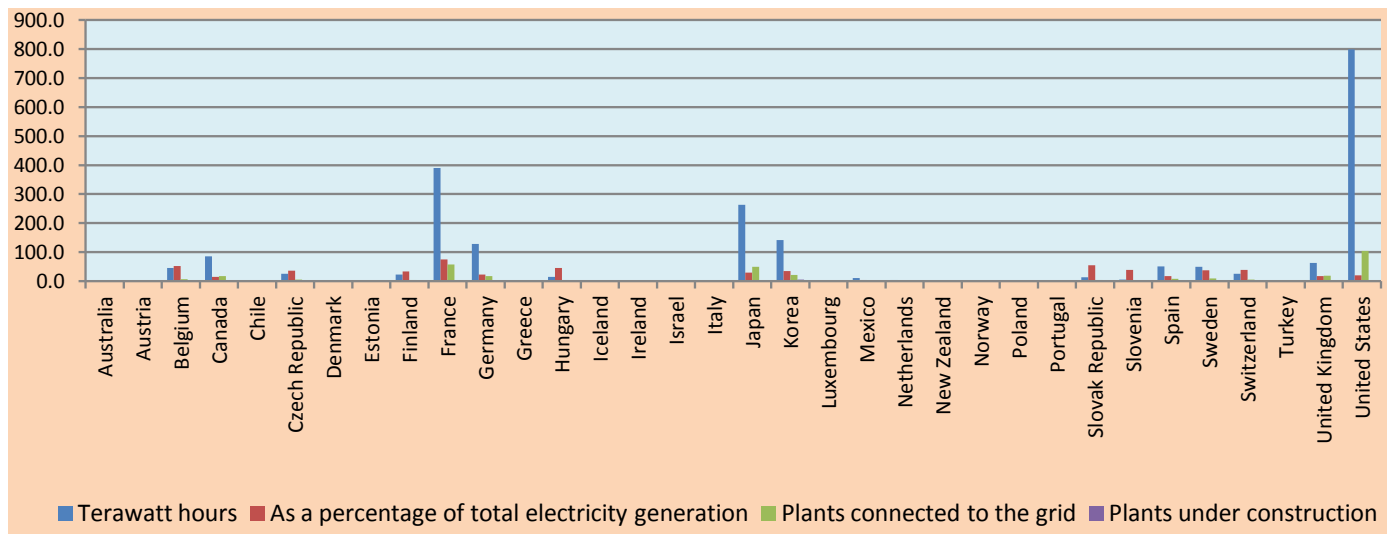

Figure 2. Nuclear electricity generation and nuclear power plants in OECD (source: own calculations using data from the OECD).

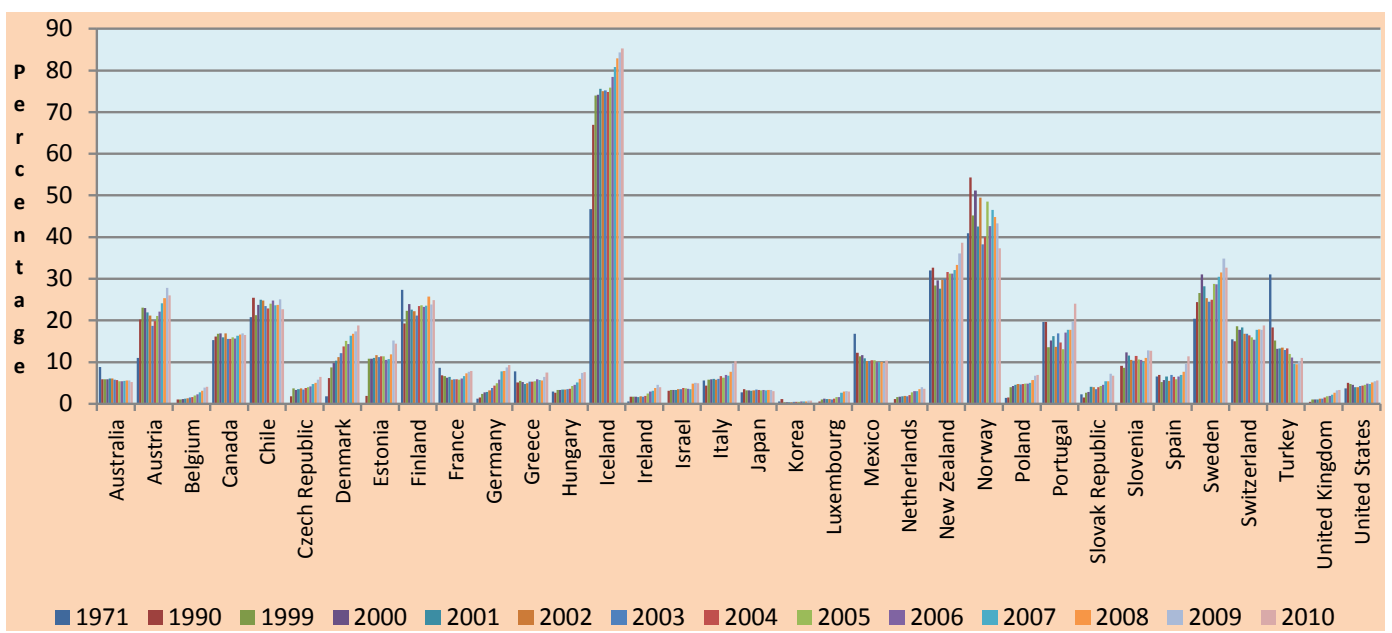

Figure 3. Contribution of renewables to energy supply in OECD (source: own calculations using data from the OECD). 
democratic and participatory institutional framework able to leverage the opportunities presented by simultaneous progress in these three areas, but progress means going one over another [5].

Similarly we must consider the definition of "environmental economics", which is regarded as a specialized branch of economics devoted to the study of environmental problems from an economic point of view. Through economic incentives and specific methodologies environmental economics is looking for solutions to the problem of incompatibility between private uses and social practices of using natural resources modifying that economic variables are pressing to a real economic levels of pollution, maximizing the welfare of present and future generations [6].

Those conceptual framework is a common factor in the protection of the environment and its implications on the quality of life by making optimal use of resources, so that the life circumstances of individuals or of society especially conditions also involving a set of existing in a place and at a given time, that influence human life and for generations to come natural, social and cultural values. It means not just the geo-space where life unfolds, but also includes living beings, objects, water, soil, air and the relationships between them, as well as intangibles such as culture [7].

Thus, both the green economy as economic cooperation are for the purposes of this paper the implementation of clean businesses that generate economic benefits in market conditions, matching action conscious manufacturing process with environmental care and quality life.

\section{The Green Economy in APEC and PA}

Among the latest actions taken by APEC in regards to green economy, the 21 members committed to prevent environmental measures could create barriers to trade, and to launch a program to promote environmental goods and services [8].

APEC members also pledged to take the first concrete steps for the liberalization of environmental goods and services by reducing tariff rates on these products to $5 \%$ or less by the end of 2015 , considering environmental goods "those who contribute directly and positively to our green growth and compliance with sustainable development objectives."

This impact relationship however is less clear in the case of the Pacific Alliance that was constituted in the April 28, 2011 by Chile, Colombia, Mexico and Peru as a conglomerate of countries to become a platform for economic integration and commercial, promoting the progressive actions towards the free movement of goods, services, capital and people.

So that the process of integration that keep the four countries of the PA, we consider of utmost importance to extend its cooperation with APEC, particularly on environmental issues where the green economy is presented as a future option to the problems of climate change, the Kyoto Protocol, as well as technological change, among others, being an alternative to address the deterioration of renewable and nonrenewable resources in the various economies of the Asia Pacific region.

We consider therefore important to establish joint strategies between APEC and the PA to address the global problem of climate change and strengthening linkages and integration into scientific generate environmental issues.

Although this type of impact between the green economy and the integration scheme involving the PA itself is not as clear as we have already mentioned, each of these individual economies has been making efforts to improve their conditions through natural design their regulations impacting the generation of green jobs for example. Hence, the authors took on the task of exploring these efforts with their results, which are shown below.

\subsection{Green Legislation}

In the case of Mexico, for example, we find the following rules [9]:

-General Law on Climate Change whose purpose is to guarantee the right to a healthy environment.

-General Law for Sustainable Forestry Development with the aim of contributing to social, ecological and environmental development.

-General Law of Ecological Balance and Environmental Protection pursued the preservation and restoration of ecological balance and environmental protection in the country.

Meanwhile Chile shows the following legislation on the subject [10]:

-Law on the Environment granted the right to live in an environment free of contamination. 
-Create Environmental Law Courts, whose function is to resolve environmental disputes within its jurisdiction.

-Law Number 20,417 referred to the submission and strategic environmental assessment of policies and plans that are generally impacting on the environment or sustainability.

Meanwhile Peru articulates its regulations on green growth and environmental protection in the following rules [11]:

-Article 304, in which it is stated that the pollution of the environment refers to environmental quality or environmental health.

-Article 307, which deal with the illegal trafficking of waste or toxic or hazardous wastes, and illegal entry into the country without proper authorization.

-Article 308, which relates to the illegal trafficking of species of wildlife and protected species and specimens.

-Article 310, refers to offenses against forests or forest formations, including the penalties for the destruction, burning, or damage in whole or in part thereof logging, be they natural or plantations.

-Article 313, refers to the alteration of the environment or landscape that contravenes the provisions of the competent authority, altering the natural environment or the urban or rural landscape, or alters the flora or fauna, by building construction or logging.

In Colombia stands out about the following standards [12]:

Law 697 of 2001, in which the rational and efficient use of energy is encouraged.

Law 728 of 2001, by which approves the Convention on the Physical Protection of Nuclear Material.

Law 6007 of 2000, which seeks to ensure rural agricultural direct technical assistance, environmental as well as on matters of waters and fisheries.

Act 740 of 2002, through which the "Cartagena Protocol on Biosafety to the Convention on Biological Diversity” was adopted.

\subsection{Green Jobs}

Green jobs are located in the center of a sustainable economy, consequently one of its key features is to develop a labor market that have decent jobs with fair pay, opportunities for both personal and professional growth and decent lifestyle and safe [13].

According to the United Nations Environment Program (UNEP), green jobs are found in many sectors of the economy, from energy supply to recycling and from agriculture to construction and transportation.

In the case of Mexico, the sectors show a higher percentage of the total environmental jobs of persons employed in economic activity are: renewable electricity (22\%); recycling (12\%); sustainable construction (11\%); forestry and reforestation (8\%) and; clean industry (7\%). The other sectors have a penetration of $6 \%$ or less in terms of persons employed: organic farming (6\%), sustainable tourism (2\%) and government (2\%).

In Chile, the Green Growth Strategy is related to the insertion of this economy to the OECD in the year 2010, on the basis of the Declaration on Green Growth (June 2009), ratified in May 2010. Therefore practices have been developed in order to promote economic growth, while contributing to the protection of the environment, creating green jobs and social equity. Notable jobs in: Agriculture; Forest management; renewable wind energy. So it is increasing sustainability and social responsibility.

In the case of Peru, the design of policies associated with green growth are linked with a framework of macroeconomic stability, so that the sustained economic growth in recent years contributed to significantly reduce poverty by increasing employment and higher household income generation, as well as through increased tax revenues resulting from the increased economic activity. In regard to green jobs in Peru are the highlights: Agriculture and forest management.

Meanwhile, Colombia shows that the most demanded categories are: Agriculture; Forest management and Environmental education.

\section{Conclusions: Supplementation of APEC and PA}

APEC considers the cooperation of different forums such as the Pacific Alliance: "We recognize the critical importance of enhancing synergies with other international fora, such as the Pacific Alliance. We instruct our Ministers and officials to participate and cooperate with these stakeholders, taking into account international 
standards acceptable to both parties.” [14].

Actually, that is in part true as with the name "Partnership Opportunities in Climate Change Research in the countries of the Pacific Alliance," 32 scientific experts from member country of the Pacific Alliance,..., met....to analyze... environmental matters." [15]. So in our opinion this network has to work closely with APEC in order to strengthen all kinds of cooperation between the two international organizations, including the issue should be included in the regional agenda considering the APEC experience.

In conclusion, we believe that there are specific conditions for a field of collaboration between APEC and the Pacific Alliance due the APEC declarations and experience; but also by the existing individual regulation in each member countries of the Pacific Alliance that we recommend as a specific item to be included in the agenda of PA without affecting free trade and investment facilitation. Bringing about an increase in green jobs, due to the policies that are being implemented in the countries of the Pacific Alliance, and other positive actions highlighting: awareness in sustainable look and care for the environment.

\section{References}

[1] OECD (2014). http://www.oecd.org/publications/factbook/

[2] IPCC (2013) Intergovernmental Panel on Climate Change. http://www.ipcc.ch/organization/organization history.shtml\#.UGI pY1lRWQ

[3] UNEP (2013) Programa Medioambiental de la ONU. http://www.unep.org/PDF/PressReleases/temperature-briefing-21-02-10-final-e.pdf

[4] (2014). http://suite101.net/article/que-es-la-economia-verde-definicion-y-conceptos-basicos-a86272

[5] (2014). http://uptparia.edu.ve/documentos/DESARROLLO\%20SUSTENTABLE.pdf

[6] (2014). http://www.banrepcultural.org/blaavirtual/ayudadetareas/economia/econo62.htm

[7] (2014). http://www.efib.m2014.net/article79.html

[8] (2014). www.apec.org

[9] (2014). http://www.diputados.gob.mx/LeyesBiblio/pdf/LGCC.pdf

[10] (2014). http://www.conaf.cl/wp-content/files_mf/1370463346Ley19300.pdf

[11] (2014). http://www.minam.gob.pe/wp-content/uploads/2013/10/07delitosambientales.pdf

[12] (2014). http://www.encolombia.com/medioambiente/hume-ley69701.htm

[13] OIT (2007). www.oei.es/pdfs/panorama_laboral_07.pdf

[14] (2014). http://www.apec.org/Meeting-Papers/LeadersDeclarations/2013/2013 aelm/2013 aelm annexA.aspx

[15] (2014).

http://alianzapacifico.net/cientificos-se-paises-de-la-alianza-del-pacifico-debatieron-en-chile-sobre-cambio-climatico/ 
Scientific Research Publishing (SCIRP) is one of the largest Open Access journal publishers. It is currently publishing more than 200 open access, online, peer-reviewed journals covering a wide range of academic disciplines. SCIRP serves the worldwide academic communities and contributes to the progress and application of science with its publication.

Other selected journals from SCIRP are listed as below. Submit your manuscript to us via either submit@scirp.org or Online Submission Portal.
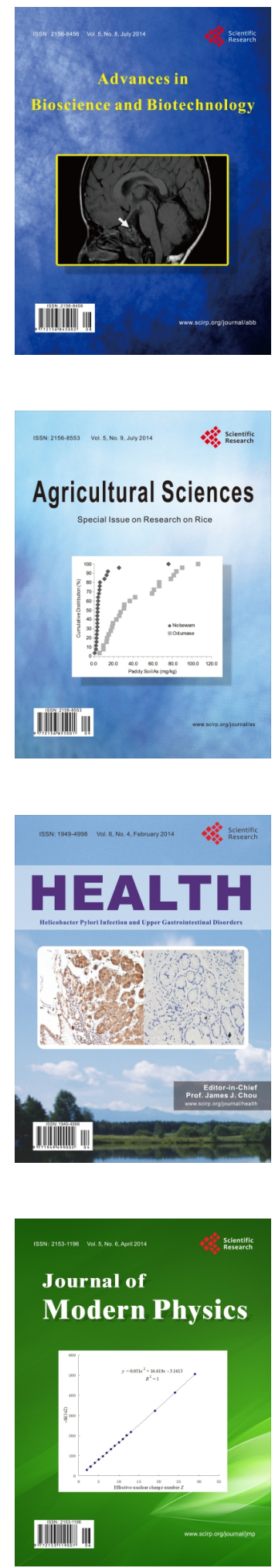
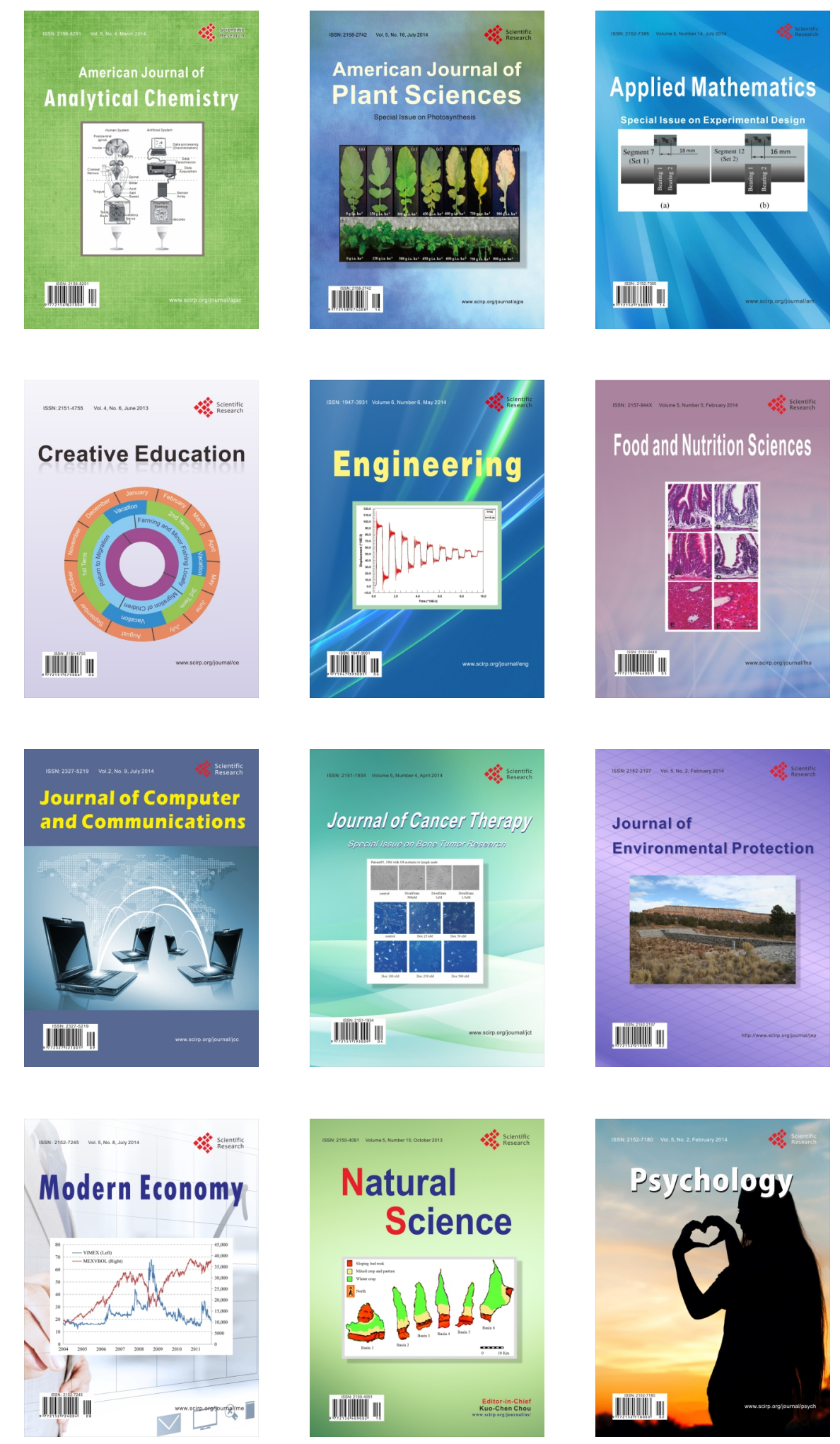